\title{
THE ROLE OF A COMMON EUROPEAN FRA- MEWORK IN THE ELABORATION OF NATIONAL LANGUAGE CURRICULA AND SYLLABUSES
}

\author{
Carlos A. M. Gouveia
}

\section{ABSTRACT:}

Following the Systemic Functional Linguistics based theory and methodology of Positive Discourse Analysis, this paper discusses some of the political, cultural and educational propositions motivating the Council of Europe's document Common European Framework of Reference for Languages. A close reading of the text clearly shows that while attempting to promote a plurilingual approach to the learning of languages in Europe, the document also calls for a change in teaching practices aiming at a transformation in the dynamics of language relations in Europe. Some of the issues focused upon in the paper derive directly from the document's stated objectives, namely questions of levelling, standardization, democracy and hegemony, on the one hand, and questions of plurality, independence, empowerment and difference, on the other.

KEY WORDS: Systemic Functional linguistics; Critical discourse Analysis; Positive discourse Analysis; Common European Framework of Reference for Languages.

INTRODUCTION $^{1}$

In the light of the theory and methodology of Systemic Functional Linguistics (SFL) and Critical Discourse Analysis (CDA), in this paper I intend to discuss some of the political, cultural and educational propositions underlying the Council of Europe's document Common European Framework of Refe-

\footnotetext{
${ }^{1}$ I would like to thank Luísa Falcão for reading and commenting on a draft of this paper. I also would like to thank the Portuguese Foundation for Science and Technology (Fundação para a Ciência e Tecnologia), for the sabbatical research grant that made the writing of the paper possible. Needless to say, responsibility for the final version lies with me.
} 
rence for Languages: Learning, Teaching, Assessment. In that sense, the paper gives voice to the purpose of thinking more politically about the various applications of SFL work, while advocating a Positive Discourse Analysis (PDA) perspective, that is, a type of analysis that does not "focus on ideologically driven discrimination, with respect to gender, ethnicity, class and related social variables" (Martin, 2004: 179), like many works on CDA do, but an analysis that aims at an "understanding of how change happens, for the better, across a range of sites - how feminists re-make gender relations in our world, how Indigenous people overcome their colonial heritage, how migrants renovate their new environments and so on" (Idem: 184).

The Common European Framework of Reference for Languages: Learning, Teaching, Assessment, hereafter referred to as Common European Framework or just Framework, was published in 2001, after ten years of preparation. As stated in its first chapter (CEF: 1), "The Common European Framework provides a common basis for the elaboration of language syllabuses, curriculum guidelines, examinations, textbooks, etc. across Europe. It describes in a comprehensive way what language learners have to learn to do in order to use a language for communication and what knowledge and skills they have to develop so as to be able to act effectively."

A close reading of the text clearly shows that, while attempting to promote a plurilingual approach to the learning of languages in Europe, so that students may be given the opportunity to develop a plurilingual competence, the document also calls for a change in teaching practices eventually aiming at a substantial improvement in the dynamics of language relations in Europe, where English is seen as having a dominant position (not least in international communication).

Some of the issues under scrutiny in my research derive directly from the document's stated objectives, namely questions of levelling, standardization, democracy and hegemony, on the one hand, and questions of plurality, independence, empowerment and difference, on the other. In this paper, though, I have chosen to concentrate only on a particular aspect of the document's discursive strategies and on how it contributes to empower its users in the prosecution of their professional activities. I will, therefore, use the next section of the paper to describe the Common European Framework and the stages it has 
gone through. The third section contains a description of the motivations for its existence and of the change it is bringing along. The fourth section will be devoted to the exemplification of the analysis, and finally, in the fifth section, I will tentatively draw some conclusions.

\section{What is the Common European Framework?}

Based on a background political will for an education in democratic citizenship at a European level (Europe, Council of Europe and European Union), the Common European Framework is a Council of Europe document whose main aim may be said to be the standardization of the discourse on language learning across Europe. Published as the result of ten-year hard work on the need to develop a common basis for the elaboration of language syllabuses, curriculum guidelines, examinations, textbooks, etc, the Common European Framework was put together as the main part of the project "Language Learning for European Citizenship" developed actively from 1991 onwards and also as the result of previous work on the description and scaling of language use and ability. By providing a reference for speaking about the learning skills, while raising awareness of them, the Common European Framework stands as a set of guidelines to be used in the description of the achievements of learners of foreign languages across Europe, and as the reference document to facilitate understanding and management between the various levels of the education world in the continent.

The Common European Framework originated in the Council of Europe, a multinational organisation that promotes cooperation among its 45 member states in areas such as law, education, culture and human rights, and which must not be mistaken for the European Union or for any of its organisations. A European Union Council Resolution dated November 2001 recommended that the Common European Framework be used in setting up systems of validation of language competences. The Framework has rapidly become the standard reference for teaching and testing languages in Europe, which clearly shows that it has in fact became "the" reference document for language learning, teaching and assessment in the entire European Union, that is, it has become "the system" (See Fulcher, 2004a e 2004b). 
The Common European Framework is a 260-page document (around 80.000 words, not counting appendixes) in the form of a book published in English by Cambridge University Press, and in other European languages by major national publishing houses. The publication and implementation of the Common European Framework as the reference document has led to the production of several guides, such as the Guide for Users (Trim, 2000), for instance, or the Language examining and test development document (Milanovic, 2002) and some evaluative publications, such as Alderson (ed., 2002) or Morrow (ed., 2004).

The Common European Framework is organized in nine chapters and four Appendixes:

1. The Common European Framework in its political and educational context

2. Approach adopted

3. Common Reference Levels

4. Language use and the language user/learner

5. The user/learner's competences

6. Language learning and teaching

7. Tasks and their role in language teaching

8. Linguistic diversification and the curriculum

9. Assessment

Appendix A: Developing proficiency descriptors

Appendix B: The illustrative scales of descriptors

Appendix C: The DIALANG scales

Appendix D: The ALTE ‘Can Do’ statements

The Common European Framework is related with another Council of Europe document, the European Language Portfolio (ELP), a personal document that stands as a mixture of a passport, a biography and a file, with documental, political and didactic functions. The European Language Portfolio is based on the Common European Framework parameters of proficiency description, the six descriptive levels, and its main political function is to allow and help incrementing the mobility of citizens in Europe by providing them with valid language proficiency criteria recognised all over the continent. 
As stated by the authors, the six common reference levels proposed by the Common European Framework are less the result of an innovative outbreak through the traditional ways of organising levels of proficiency than the result of a new way of looking at the classic division into basic, intermediate and advanced (CEF: 22-23):

There does appear in practice to be a wide, though by no means universal, consensus on the number and nature of levels appropriate to the organisation of language learning and the public recognition of achievement. It seems that an outline framework of six broad levels gives an adequate coverage of the learning space relevant to European language learners for these purposes. (...) When one looks at these six levels, however, one sees that they are respectively higher and lower interpretations of the classic division into basic, intermediate and advanced.

The six common reference levels proposed by the document and shown in the table below are then the result of an established consensus and at the same time represent an adequate coverage of the different types of users:

\begin{tabular}{|c|l|c|l|}
\hline \multirow{2}{*}{ A } & \multirow{2}{*}{ Basic User } & A1 & Breakthrough \\
\cline { 3 - 4 } & & A2 & Waystage \\
\hline \multirow{2}{*}{ B } & \multirow{2}{*}{ Independent User } & B1 & Threshold \\
\cline { 3 - 4 } & & B2 & Vantage \\
\hline \multirow{2}{*}{ C } & \multirow{2}{*}{ Proficient User } & C1 & Effective Operational Proficiency \\
\cline { 3 - 4 } & & C2 & Mastery \\
\hline
\end{tabular}

Table 1 - The six common reference levels proposed by the document

The description of each of these six common reference levels may be presented in different ways, depending on the different purposes they are supposed to serve. That description may also evolve over time, based on the expertise incorporated into it. Nevertheless, as stressed by the authors of the document, "For some purposes it will be appropriate to summarize the set of proposed Common Reference Levels in single holistic paragraphs": 


\begin{tabular}{|l|l|l|}
\hline Proficient User & C2 & $\begin{array}{l}\text { Can understand with ease virtually everything heard or } \\
\text { read. Can summarise information from different spoken } \\
\text { and written sources, reconstructing arguments and accounts } \\
\text { in a coherent presentation. Can express him/herself spon- } \\
\text { taneously, very fluently and precisely, differentiating finer } \\
\text { shades of meaning even in more complex situations. }\end{array}$ \\
\hline C1 & $\begin{array}{l}\text { Can understand a wide range of demanding, longer texts, } \\
\text { and recognise implicit meaning. Can express him/her- } \\
\text { self fluently and spontaneously without much obvious } \\
\text { searching for expressions. Can use language flexibly and } \\
\text { effectively for social, academic and professional purposes. } \\
\text { Can produce clear, well-structured, detailed text on com- } \\
\text { plex subjects, showing controlled use of organisational } \\
\text { patterns, connectors and cohesive devices. }\end{array}$ \\
\hline Independent & B2 & $\begin{array}{l}\text { Can understand the main ideas of complex text on both con- } \\
\text { crete and abstract topics, including technical discussions in } \\
\text { his/her field of specialisation. Can interact with a degree } \\
\text { of fluency and spontaneity that makes regular interaction } \\
\text { with native speakers quite possible without strain for either } \\
\text { party. Can produce clear, detailed text on a wide range of } \\
\text { subjects and explain a viewpoint on a topical issue giving } \\
\text { the advantages and disadvantages of various options. }\end{array}$ \\
\hline B1 & $\begin{array}{l}\text { Can understand the main points of clear standard input on } \\
\text { familiar matters regularly encountered in work, school, } \\
\text { leisure, etc. Can deal with most situations likely to arise } \\
\text { whilst travelling in an area where the language is spoken. } \\
\text { Can produce simple connected text on topics which are } \\
\text { familiar or of personal interest. Can describe experiences } \\
\text { and events, dreams, hopes and ambitions and briefly give } \\
\text { reasons and explanations for opinions and plans. }\end{array}$ \\
\hline
\end{tabular}




\begin{tabular}{|l|l|l|}
\hline Basic User & A2 & $\begin{array}{l}\text { Can understand sentences and frequently used expressions } \\
\text { related to areas of most immediate relevance (e.g. very } \\
\text { basic personal and family information, shopping, local } \\
\text { geography, employment). Can communicate in simple and } \\
\text { routine tasks requiring a simple and direct exchange of } \\
\text { information on familiar and routine matters. Can describe } \\
\text { in simple terms aspects of his/her background, immediate } \\
\text { environment and matters in areas of immediate need. }\end{array}$ \\
\cline { 2 - 2 } & $\begin{array}{l}\text { Can understand and use familiar everyday expressions and } \\
\text { very basic phrases aimed at the satisfaction of needs of a } \\
\text { concrete type. Can introduce him/herself and others and } \\
\text { can ask and answer questions about personal details such } \\
\text { as where he/she lives, people he/she knows and things he/ } \\
\text { she has. Can interact in a simple way provided the other } \\
\text { person talks slowly and clearly and is prepared to help. }\end{array}$ \\
\hline
\end{tabular}

Table 2 - Common Reference Levels summary

The Framework also allows for a finer up- or downgrading of the scaling system by subdividing the levels and further detailing the associated descriptors.

\section{Politics, power and language Learning}

In the "Preface" to the 1980 edition of Threshold Level English (van Ek, 1980), a document of seminal importance for the later creation of the Common European Framework, it is stated that its purpose is to "convert language teaching from structure-dominated scholastic sterility into a vital medium for the freer movement of people and ideas". By advocating such a communicative approach to language teaching, Threshold Level English opens up the way to a distinction between theories: some, like the ones in general and formal linguistics, are sterile and do not contribute to teaching as a medium for the freer movement of people and ideas; others, such as the ones in applied linguistics, are not sterile and contribute to teaching as a medium for the freer movement 
of people and ideas. The Common European Framework carries this connection between language teaching and "the freer movement of people and ideas" even further by justifying part of its existence as a reference document with the political interests of the Committee of Ministers and of Heads of State of the Council of Europe, who had warned against "the dangers that might result from the marginalisation of those lacking the skills necessary to communicate in an interactive Europe" and who "identified xenophobia and ultra-nationalist backlashes as a primary obstacle to European mobility and integration, and as a major threat to European stability and to the healthy functioning of democracy" (CEF: 4).

By connecting citizenship education with foreign language teaching, the Framework is in fact stressing that intercultural competence and critical cultural awareness are not only a matter of language teaching but also of citizenship education. Notice for instance how the document deals with the voices of political authorities on the first pages of its introduction, where it construes itself as answering a priority educational objective, that of preparing for democratic citizenship and of strengthening "independence of thought, judgement and action, combined with social skills and responsibility":

Particular urgency was attached to these objectives by the First Summit of Heads of State, which identified xenophobia and ultranationalist backlashes as a primary obstacle to European mobility and integration, and as a major threat to European stability and to the healthy functioning of democracy. The second summit made preparation for democratic citizenship a priority educational objective, thus giving added importance to a further objective pursued in recent projects, namely:

To promote methods of modern language teaching which will strengthen independence of thought, judgement and action, combined with social skills and responsibility. 
In the light of these objectives, the Committee of Ministers stressed 'the political importance at the present time and in the future of developing specific fields of action, such as strategies for diversifying and intensifying language learning in order to promote plurilingualism in a pan-European context' and drew attention to the value of further developing educational links and exchanges and of exploiting the full potential of new communication and information technologies.

Quoting from the political and institutional agenda that motivates the Council of Europe's projects and policies, the authors of the Framework present their work not as just a project for the standardization of the discourse on language learning or of the description of achievements of learners of foreign languages across Europe, but as a fundamental instrument, whose purpose is to contribute with the full expression of citizenship, the development of democracy and the mobility and integration of citizens to a pan-cultural Europe.

Notice for that matter that the entire discourse of authority upon which the document draws is introduced by a statement about the purposes that the Common European Framework is called to serve (CEF: 2):

CEF serves the overall aim of the Council of Europe as defined in Recommendations R (82) 18 and R (98) 6 of the Committee of Ministers: 'to achieve greater unity among its members' and to pursue this aim 'by the adoption of common action in the cultural field'.

In the light of what is stressed in the introduction, one must admit, therefore, that regardless of its results in the different areas of language teaching and learning to which it applies, the Framework is, then, an exemplary case study in the way political and social wills or agendas can foster important linguistic research and have an impact on the methodologies and practices of language learning and teaching. Considering that these are highly valued principles of social justice and integration, we may actually say that it is extremely positive that they were the Framework's motivations. In much the same way, it is also highly positive that, when it comes to establishing the set of common reference points and descriptors to be used when 
assessing proficiency, the emphasis is now laid on what learners can or are able to do instead of on what they cannot or are not able to do. The "can do" statements or descriptors are "a set of performance-related scales, describing what learners can actually do in the foreign language" (CEF, Appendix D, p. 244). As such they are not only user-oriented scales but also scales that represent positively the whole enterprise of learning a foreign language.

The Common European Framework may well stand as an example of how change is brought about in the world of language teaching and learning in Europe, and how that change can be for the better. In that sense it may be said to require a positive discourse analysis, that is, a discourse analysis with "a complementary focus on how social subjects design change", as Martin (2000: 122) has put it. As Martin goes on saying, "If we understood change for the better, then we could use these understandings to inform our interventions in whatever practice is undertaken. We could stop being so monologically depressing all the time when talking about language and power."

Now, I am perfectly aware that the change I am talking about here is not produced by either the regularity of discursive practices in the world of language teaching and learning nor by the contestation of that same regularity. On the contrary, this change is currently made possible by political enforcement, that is, by a political agenda that owes nothing to language teaching and learning and that in all probability was not intended to have anything to do with it. But, again, one should not forget that, despite its political motivation, the Common European Framework is designing change and that change will positively affect the life of individuals. Paraphrasing Martin's words just quoted, we do not have to look at all the examples of government law or policy enforcement as "monologically depressing". They may actually be seen as dialogically constructed and as the result of a joint effort of political will and professional expertise with a positive purpose.

\section{CHOICES FOR THE EMPOWERMENT OF USERS}

The producers of the Framework know only too well that social accountability and responsibility, in the light of the political implications and presuppositions motivating the reasoning behind the document, is in direct opposition 
to imposition and enforcement. Hence their effort to make clear that one of the characteristics of the document is its adaptability (CEF: 7) and possibility of use in particular contexts, as stressed in the following quote: "The construction of a comprehensive, transparent and coherent framework for language learning and teaching does not imply the imposition of one single uniform system. On the contrary, the framework should be open and flexible, so that it can be applied, with such adaptations as prove necessary, to particular situations."

The contents of this quote show that a discourse analysis of the document may be anything but depressing, as there is no hidden agenda here. In fact, the examples that construe readers as perfectly skilled, independent, and critical subjects capable of making their own decisions and of using the Framework according to their specific needs are abundant. Another example worth quoting is the paragraph that comes immediately after the one just quoted, which states what the Common European Framework should be/is, and once again stresses the refusal by its authors of any hegemonic theory or practice in linguistics and education (CEF: 7-8):

CEF should be:

- multi-purpose: usable for the full variety of purposes involved in the planning and provision of facilities for language learning

- flexible: adaptable for use in different circumstances • open: capable of further extension and refinement

- dynamic: in continuous evolution in response to experience in its use

- user-friendly: presented in a form readily understandable and usable by those to whom it is addressed

- non-dogmatic: not irrevocably and exclusively attached to any one of a number of competing linguistic or educational theories or practices."

It is exactly this spirit of non-imposition and of freedom of use that makes the Common European Framework a good example of a discourse with an empowering attitude. It is interesting to notice that, as a consequence of this willingness to be non-dogmatic, the Common European Framework discursi- 
vely builds its impartiality when it comes to theory picking. Here are the four examples of theory picking found in the text: one on language acquisition, one on language competence, one on grammar and one on learning:

1 [CEF] cannot take up a position on one side or another of current theoretical disputes on the nature of language acquisition and its relation to language learning, nor should it embody any one particular approach to language teaching to the exclusion of all others. (p. 18)

2 The description also needs to be based on theories of language competence. This is difficult to achieve because the available theory and research is inadequate to provide a basis for such a description. Nevertheless, the categorisation and description needs to be theoretically grounded. In addition, whilst relating to theory, the description must also remain user-friendly - accessible to practitioners. (p. 21: On the criteria for descriptors for Common Reference Levels)

3 Grammatical competence is the ability to understand and express meaning by producing and recognising well-formed phrases and sentences in accordance with these principles (as opposed to memorising and reproducing them as fixed formulae). The grammar of any language in this sense is highly complex and so far defies definitive or exhaustive treatment. There are a number of competing theories and models for the organisation of words into sentences. It is not the function of the Framework to judge between them or to advocate the use of any one, but rather to encourage users to state which they have chosen to follow and what consequences their choice has for their practice. Here we limit ourselves to identifying some parameters and categories which have been widely used in grammatical description. (p. 113)

4 There is at present no sufficiently strong research-based consensus on how learners learn for the Framework to base itself on any one learning theory. Some theorists believe that the human informationprocessing abilities are strong enough for it to be sufficient for a 
human being to be exposed to sufficient understandable language for him/her to acquire the language and be able to use it both for understanding and for production. They believe the 'acquisition' process to be inaccessible to observation or intuition and that it cannot be facilitated by conscious manipulation, whether by teaching or by study methods. For them, the most important thing a teacher can do is provide the richest possible linguistic environment in which learning can take place without formal teaching. (p.139)

One can notice a sort of discursive evolution from one fragment to the other in terms of the main participant in the transitivity processes (Halliday, 2004): in fragment one, the main participant is the document ("CEF"); in fragment two, particular actions get that role - "description", "the available theory and research", "the categorisation and description"; in fragment three, the main participant is first "competing theories and models", then the document again ("the function of the Framework"), and finally the authors of the document ("we"); in fragment four, we have "consensus" first, then "some theorists" and its substituting pronoun "they", and finally "the most important thing a teacher can do". From "CEF" in the first fragment to "some theorists" in the last one, what we have is the passage from very precise theory-less fields and actions to some imprecise, non-unified theoretical thinking ("some theorists believe"). Notice, for that matter, how in the last fragment "some scientists" become a circumstance of Angle ("For them") in a declarative and highly assertive identifying relational process that resumes not only the non-unified theoretical thinking just reported but also the general theoretical framing of the document. There is, in fact, a theoretical motivation backing up the theory-less attitude of the document, which of course serves, as I see it, an empowering policy-making principle in educational politics on the part of the authors of the Common European Framework.

For instance, an analysis of the (Attributive) Relational processes with language as Carrier (Halliday, 2004), which presumably construe definitions of what language is, clearly shows that the authors of the document do hold a precise and clear view on the nature of language. Notice, for that matter, the following Attributes (my emphasis): 
1 Language is not only a major aspect of culture, but also a means of access to cultural manifestations. (p.6)

2 (...) language in use varies greatly according to the requirements of the context in which it is used. In this respect, language is not a neutral instrument of thought like, say, mathematics. The need and the desire to communicate arise in a particular situation and the form as well as the content of the communication is a response to that situation. (pp. 44-45)

3 No complete, exhaustive description of any language as a formal system for the expression of meaning has ever been produced. Language systems are of great complexity and the language of a large, diversified, advanced society is never completely mastered by any of its users. Nor could it be, since every language is in continuous evolution in response to the exigencies of its use in communication. (p. 109)

4 (...) a language is a highly complex symbolic system. (p. 116)

5 (...) language is a sociocultural phenomenon (...). (p. 118)

Everybody, including the authors of the document, holds beliefs about the nature of language. Such beliefs, and beliefs about the nature of the language-leaning process, are also present in syllabus design, in course study plans and in curriculum guidelines, and they are the result of the theory their authors hold. The above-mentioned attributes given to language are not merely the result of a common-sense view of language. They are in fact theoretical constructs on the nature of language. This is so much the case that we may actually say that the authors of the Common European Framework are here advocating a functionalist theory of language. And one has to give them credit for not acknowledging it explicitly in the document. As we also have to give them credit for continuously refusing to take sides on competing theories and methodologies and for omitting any references to them.

One final example of the empowering principle underlying the Common European Framework may be seen in the fifty-nine discursive constructions scattered along the document, which point out to particular aspects users should take into consideration. Introduced by the wording "Users of the Framework may wish to consider and where appropriate state...", these attention callers 
prompt users to take position on issues spanning from such complex ones as what theory of language learning to follow to more prosaic ones such as acknowledging the purposes for language learning:

Users of the Framework may wish to consider and where appropriate state the assumptions concerning language learning on which their work is based and their methodological consequences. (p. 140) Users of the Framework may wish to consider and where appropriate state:

- for what purposes the learner will need, or wish/be equipped/be required to read;

- in which modes the learner will need or wish/be equipped/be required to read. (p. 71)

Whilst not taking a stance on sensitive matters that may deter users, the Common European Framework encourages readers to clearly state all the relevant matters related to their work with the Framework. Instead of constraining them in their decision making, the document gives users the information, the materials and the urge to actually make decisions, with an empowering attitude rarely seen in documents of this kind.

\section{Conclusion}

For some of its critics, the Common European Framework seems to lack precise directive instructions. Keddle (2004), for instance, accuses the document of ignoring grammar, and urges instructors not to ignore it when incorporating the document's approach at the secondary level. But one must wonder if Keddle's requirement concerning the Common European Framework is in fact a valid one, considering the author's views on grammar as stated on page 123 (my emphasis):

Grammatical competence is the ability to understand and express meaning by producing and recognising well-formed phrases and sentences in accordance with these principles (as opposed to me- 
morising and reproducing them as fixed formulae). The grammar of any language in this sense is highly complex and so far defies definitive or exhaustive treatment. There are a number of competing theories and models for the organisation of words into sentences. It isnotthefunctionoftheFrameworktojudgebetweenthemortoadvocatethe use ofanyone, butrathertoencourage users tostate which theyhavechosen to followand whatconsequences theirchoicehas fortheirpractice. Herewe limitourselvestoidentifyingsomeparametersandcategorieswhichhavebeen widely used in grammatical description.

In general, the critics of the Common European Framework may be said to fall into two apparently opposing categories: on the one hand, those that stress the negative aspect of the process of standardisation associated with the document (Fulcher, 2004a and 2004b, for instance) and, on the other, those that would like it to be more precise, accurate and directive (Keddle, 2004, Weir, 2005). Curiously enough, none of the critics in these categories is actually against the existence of a Common European Framework; but whereas one group accuses it of having gone too far, the other blames it for not having gone far enough. Virtue definitely stands in the middle, and the ability to strike a happy medium is indeed a virtue of the Common European Framework.

It would be nice to finish on such a positive note, but let me go a little bit further and quote one the authors of the Common European Framework (North, 2004), in his reply to some of its critics:

The CEF draws on theories of communicative competence and language use in order to describe what a language user has to know and do in order to communicate effectively and what learners can typically be expected to do at different levels of proficiency. It doesn't try to define what should be taught (content specifications), let alone state how it should be taught (methodology). Content specifications differ according to the target language and the context of the learning; methodology varies with pedagogic culture. 
That Brian North had to write these words speaks volumes for the document's value and the hope that its authors have put into it. But in the light of my reading, this quote also shows how the document seems to have been misread by some of its critics, and how unfortunately even discourses of hope can actually be accused of being intrusive, authoritarian and disempowering. It seems that peace and reconciliation are not always brought about by sheer hope.

\section{REFERENCES}

ALDERSON,J.C.(org.)CommonEuropeanFrameworkofReferenceforLanguages: learning, teaching, assessment: case studies. Strasbourg: Council of Europe Language Policy Division, 2002.

COUNCIL OFEUROPE. Common European Framework of Reference for Languages: learning, teaching, assessment. Cambridge: Cambridge University Press, 2001.

FULCHER, G. Are Europe's tests being built on an 'unsafe' framework? Guardian Weekly, March 18th, 2004a.

FULCHER, G. Deluded by Artifices? The Common European Framework and Harmonization. Language Assessment Quarterly, 1(4): 252-266, $2004 \mathrm{~b}$.

HALLIDAY, M. A. K. An Introduction to Functional Grammar. 3 ed. revised by C. M. I. M. Matthiessen. London: Arnold, 2004.

KEDDLE, J.S. The CEF and the secondary school syllabus. In: K. Morrow (org.) Insights from the Common European Framework. Oxford: Oxford University Press, 2004, pp. 43-54.

MARTIN, J. R. Design and practice: enacting functional linguistics. Annual Review of Applied Linguistics, 20: 116-126, 2000.

MARTIN, J. R. Positive Discourse Analysis: Solidarity and Change. Revista Canaria de Estudios Ingleses, 49: 179-200, 2004.

MILANOVIC, M. (org.) Language examining and test development. Strasbourg: Council of Europe Language Policy Division, 2002.

MORROW, K. (org.) Insights from the Common European Framework. Oxford: Oxford University Press, 2004.

NORTH, B. Europe's framework promotes language discussion, not directives. Guardian Weekly, April 15th, 2004. 
TRIM,J.L.M. etal. Common European Framework of Reference for Languages: Learning, teaching, assessment-A Guide for Users. Strasbourg: Council of Europe Language Policy Division, 2002.

VAN EK, J. A. Threshold Level English. London: Pergamon Press, 1980.

WEIR, C. J. Limitations of the Common European Framework for developing comparable examinations and tests. Language Testing, 22 (3): 281-300, 2005 . 